\title{
FUNDAMENTALIDAD DEL DERECHO A LA PROTECCIÓN DE LA SALUD Y SOSTENIBILIDAD DEL SISTEMA PÚBLICO DE SALUD (CUANDO MÁS PUEDE SER MENOS)
}

\author{
FEDERICO DE MONTALVO JÄÄSKELÄINEN \\ Profesor propio agregado $D .{ }^{\circ}$ Constitucional \\ UPCOmillas (ICADE)
}

\begin{abstract}
SUMARIO
I. Introducción. II. La novedad del viejo debate sobre la naturaleza del derecho a la protección de la salud. III. Empoderamiento del intérprete de la Constitución y consiguiente debilitamiento del derecho a la protección de la salud: las razones de la paradoja. IV. La objeción del Tribunal de Justicia como actor principal en la distribución del gasto público. V. La objeción de la litigación como elemento principal de justicia social en sanidad. VI. Conclusión: hacia una fórmula intermedia de control del derecho a la protección de la salud
\end{abstract}

\section{INTRODUCCIÓN}

El derecho a la protección de la salud es uno de los proclamados constitucionalmente dentro de la categoría de los que reciben la común denominación de derechos sociales $^{1}$, situado, por tanto, dentro de los principios rectores ${ }^{2}$. Se trata de un derecho que, como ocurre con algún otro de la misma categoría (véase, en

1 Delgado del Rincón nos recuerda que nuestra Constitución no consagra el derecho a la salud, es decir, un derecho a ser curado, porque su garantía es imposible, es una «fantasía», y que ninguna acción humana puede garantizar a todos la salud. Se garantiza un derecho a la protección de la salud que se traduce en la cobertura sanitaria a través de unas prestaciones que se integran en el servicio público. Vid. L.E. DeLGADO DEL RINCón, El derecho a la asistencia sanitaria de los extranjeros: limitaciones y problemas competenciales, Tirant lo Blanch, Valencia, 2019, pp. 27 y 28.

2 Se trataría, en palabras de Rey Martínez, de un derecho legal y no de un derecho fundamental. Vid. F. Rey Martínez, «Protección de la salud, atención primaria y derechos fundamentales», Teoría y Realidad Constitucional, n. ${ }^{\circ} 41,2018$, p. 290. 
especial, los derechos a disfrutar de una vivienda y de un medio ambiente adecuado para el desarrollo de la persona), parece estar de manera permanente en búsqueda de su verdadera eficacia o, incluso, de su naturaleza, aunque en palabras de Escobar Roca, se trataría más bien de la búsqueda de la primera, ya que la división en bloques del Título I no serviría para distinguir entre tipos de derechos fundamentales, sino para diferenciar entre niveles de garantía ${ }^{3}$.

La inquietud que la ubicación de dicho derecho entre los principios rectores ha generado, sobre todo, en los sectores más progresistas de la doctrina ha cobrado cierta fuerza en esta década tras la reciente crisis económica ${ }^{4}$ y el impacto que en el Estado social parecen haber tenido determinadas decisiones políticas y jurídicas de contención del gasto público, singular, aunque no exclusivamente, en el ámbito del Sistema Nacional de Salud.

No es que la cuestión de la naturaleza del derecho a la protección de la salud fuera pacífica en décadas pasadas, pero sí que es cierto que, al menos, el debate doctrinal no había ocupado tantas páginas en la literatura científica, considerándose como momento culmen la aprobación por el anterior Gobierno del Partido Popular del controvertido Decreto-ley 16/2012, de 20 de abril, de medidas urgentes para la garantizar la sostenibilidad del Sistema Nacional de Salud y mejorar la calidad y seguridad de sus prestaciones. Esta norma vino a transformar o, en términos más correctos, a revertir la naturaleza del propio sistema público de salud, transformando su carácter universal en un modelo basado en el prerrequisito de ostentar la condición de asegurado o beneficiario, en términos similares a las existentes previamente a la aprobación de la Ley 49/1998, de 30 de diciembre, de Presupuestos Generales del Estado para 1999, que dispuso que sería el Estado, a través de las transferencias presupuestarias a las comunidades autónomas, el que asumiría totalmente la financiación pública de la asistencia sanitaria, desvinculándose con ello la asistencia sanitaria de las aportaciones a la Seguridad Social. El modelo Beveridge inaugurado en 1999 pareció revertir en el anterior modelo, más similar al denominado Bismarck. Además, el mismo Decreto-ley excluyó de la cobertura o, al menos, la limitó a grupos sociales especialmente vulnerables como es el de los inmigrantes indocumentados.

La aprobación de dicha norma y su posterior validación por el Tribunal Constitucional mediante Sentencia 139/2016, de 21 de julios , provocó en cierto sector

3 G. Escobar Roca, Nuevos derechos y nuevas garantías de los derechos, Marcial Pons, Madrid, 2019, p. 41.

4 Vid. J.F. PÉrez GÁLVEZ, «La e-Salud: retos que plantea la evolución tecnológica y su incidencia sobre el sistema sanitario», Derecho y Salud, vol. 25, 2015, pp. 18 a 21.

5 Sobre dicha polémica Sentencia del Tribunal Constitucional se han publicado diferentes e interesantes trabajos por parte de la doctrina española. Entre ellos, pueden destacarse los siguientes: J. L. Monereo Pérez y L. A. Triguero MARTíNEZ, «Un revés en la evolución progresiva del workfare state: la regresión en la tendencia hacia la universalidad del derecho constitucional a la asistencia sanitaria. A propósito de la STC 139/2016», Derecho de las relaciones laborales, núm. 2, 2017, pp. 177 y ss.; L. E. DELGADO DEL RinCón, «El derecho a la protección de la salud de los inmigrantes en situación administrativa irregular: reflexiones críticas sobre la reciente jurisprudencia 
de la doctrina la necesidad de garantizar el derecho a la protección a la salud frente a los avatares y veleidades de la economía y del gasto público mediante su incorporación a los derechos reconocidos constitucionalmente como fundamentales, es decir, en términos más gráficos, la subida a un escalón o nivel superior de tal derecho. Curiosamente, la propuesta de dicho sector, como veremos ahora, otorga la última palabra al poder que terminó por refrendar la reversión del modelo.

Pues bien, a través del presente trabajo vamos a sostener que dicha propuesta de dotar de fundamentalidad al derecho a la protección de la salud mediante una pretendida reforma constitucional y con la pretensión de fortalecerlo y blindarlo frente a los avatares económicos y políticos, no resulta, en primer lugar, necesaria en aras de proteger tal derecho, lo que puede alcanzarse a través del efectivo control de la labor del ejecutivo y del legislador que el citado artículo 53.3 atribuye al Poder Judicial, en general, y al Tribunal Constitucional, en particular, es decir, a través de una correcta interpretación del derecho y de la propia Constitución in toto. En nuestra opinión, el ordenamiento constitucional y la propia doctrina del Tribunal Constitucional ofrecen herramientas jurídicas suficientes para llevar a cabo un control más intenso del derecho a la protección a la salud, de manera que el problema no estaría tanto en la ausencia de dichas herramientas en nuestro sistema constitucional por carecer el derecho de naturaleza fundamental, sino en su incorrecta interpretación y aplicación por los Tribunales. El problema no está, como mantendremos, en el propio texto constitucional, sino en la interpretación que han hecho los Tribunales y, sobre todo, el Tribunal Constitucional, siendo un ejemplo paradigmático de ello la precitada STC 139/2016.

En segundo lugar, sostendremos también que dotar de fundamentalidad al derecho a la protección de la salud no solo incide en la propia división de poderes, como han sostenido tradicionalmente importantes sectores de la doctrina en su defensa de un control judicial limitado de los derechos con alto impacto económico, sino que además puede afectar a la propia sostenibilidad del sistema público de salud. A estos efectos, nos remitiremos a los trabajos que sobre el papel de la litigación en la defensa del derecho a la salud ha llevado a cabo importantes sectores de la doctrina extranjera y algún autor en España, para demostrar que dotar de fundamentalidad a tal derecho no cumple, paradójicamente, la función de una distribución justa y equitativa del derecho y de los recursos que conlleva el mismo. También, nos valdremos a tal fin de la experiencia de algunos Estados que, con el propósito de blindar al derecho a la protección de la salud, han dotado al mismo de naturaleza

constitucional acerca de las restricciones introducidas por el Decreto-ley 16/2012, de 20 de abril», Revista Española de Derecho Constitucional, núm. 112, 2018; M. Hernández Ramos, «La respuesta del Tribunal Constitucional a los Decretos-Leyes en materia de derechos sociales. El criticable retroceso de la jurisprudencia constitucional», Revista Vasca de Administración Pública, núm. 109, 2017; I. Sobrino GujjARro, «Contenido constitucional del derecho a la protección de la salud a la luz de la STC 139/2016», Ius et Scientia, núm. 1, 2017; y N. SANGüESA Ruíz, «Exclusión de los extranjeros en situación irregular del acceso gratuito al Sistema público de salud en España. Sentencia 139/2016 del Tribunal Constitucional», Biolaw Journal-Rivista di BioDiritto, núm. 1, 2017. 
fundamental, ya sea expresamente en el texto constitucional o extramuros a través de la doctrina constitucional, facilitando así el acceso a los Tribunales de Justicia y provocando, por un ende, un peligroso protagonismo de dichos Tribunales en la distribución y determinación de los recursos económicos.

\section{LA NOVEDAD DEL VIEJO DEBATE SOBRE LA NATURALEZA DEL DERECHO A LA PROTECCIÓN DE LA SALUD}

La dificultad que encuentra el derecho a la protección de la salud, como ocurre en general con otros derechos sociales, para alcanzar una mayor eficacia, en términos equiparables o similares a los que ostentan los derechos fundamentales, quizás sea en parte debido a que su recepción en los textos constitucionales se produjera mucho más tardíamente que la de las libertades fundamentales. Como nos recuerda Escobar Roca, la proyección del Estado social sobre los derechos fundamentales se ha movido en una doble dirección, para garantizar que determinadas actuaciones de los trabajadores cuya finalidad es luchar por la mejora de sus condiciones de vida queden protegidas de intromisiones externas, al modo de los derechos de libertad, y para concretar las prestaciones que el Estado debe satisfacer en su obligación de luchar por la igualdad material, suministrando a todos los ciudadanos la llamada procura existencial. Sin embargo, si bien las libertades sindicales y de huelga han encontrado fácil acomodo en los textos constitucionales (quizás por disponer de una naturaleza y características similares a las de las libertades tradicionales), y más aún cuando se vencieron los temores a la eficacia de los derechos en las relaciones entre particulares, no sucede lo mismo con los derechos de prestación, cuyo reconocimiento suele resultar controvertido ${ }^{6}$. Como puede verse, y como nos recuerda Pérez-Luño, la expresión derechos sociales no posee un significado unívoco, englobando categorías muy heterogéneas cuyo único punto común de referencia viene dado por su tendencia a pormenorizar las exigencias que se desprenden del principio de la igualdad ${ }^{7}$.

El debate sobre la verdadera eficacia y fuerza vinculante del derecho a la protección de la salud no es nuevo, pero ha recobrado cierta actualidad en nuestra doctrina como consecuencia de la crisis económica y de las medidas de estabilidad presupuestaria que ésta ha conllevado y su impacto inmediato en su eficacia, sobre todo, a partir del precitado Decreto-ley 16/2012.

Las amplias facultades que se reconocen al legislador y al propio ejecutivo como consecuencia de la inclusión del derecho a la protección de la salud dentro de nuestro sistema constitucional en la categoría de los principios rectores, no ha

6 G. Escobar Roca, «Derechos fundamentales: una aproximación general», Anuario de la Facultad de Derecho de la Universidad de Alcalá de Henares, n. ${ }^{\circ}$ VIII, 1998-1999, p. 132.

7 A.E. Perez Luño, «Los derechos sociales y su status normativo en la Constitución Española», Documentación Administrativa, n. ${ }^{\circ}$ 271-272, 2005, p. 16. 
estado nunca exenta de cierto recelo y crítica, por parte, fundamentalmente, de los sectores más firmemente defensores de un modelo de justicia basado en los derechos sociales, inquietados por las consecuencias que en determinados momentos de inestabilidad económica ello pudiera conllevar. Sin embargo, la crisis transformó, en cierto modo, los temores en realidad, enfrentándonos, en palabras de algunos, a un verdadero desmoronamiento del Estado social, con la transformación de éste en una modalidad de Estado liberal o, más acertadamente, un nuevo Estado neoliberal. En este nuevo marco que se desarrolla como consecuencia de la crisis el Estado no desaparece del mercado, antes al contrario, la crisis le obliga a retomar la intervención a través de la regulación del sector financiero. El Estado en reacción a la crisis pasa de ofrecer prestaciones, actuando directamente, a dirigir. El Estado prestacional clásico del Estado social se transforma en Estado garante ${ }^{8}$.

Al mismo tiempo que el Estado vuelve a hacer acto de presencia en los mercados financieros, desaparece de los derechos sociales, o, al menos, cede su protagonismo a favor de los agentes privados, ya que el crecimiento imparable de la prima de riesgo y de los intereses de la deuda pública contraída para sostener tales derechos hace temer por la propia sostenibilidad del modelo. Se produce, por tanto, un doble efecto: más Estado en los mercados, aunque sea regulatoriamente, pero menos Estado en los derechos sociales o, al menos, en alguno de ellos, como es el derecho a la protección de la salud.

La reducción del gasto público al que hemos asistido en los últimos años no es debido únicamente a una mejora en la gestión y en el uso de los recursos económicos, sino también a una reducción en la propia inversión pública. Un ejemplo paradigmático de ello, por el importe de gasto que supone y por su directa conexión con uno de los principales derechos sociales es el gasto público en el sistema público de salud que, frente a representar un 6,4 por ciento del PIB en 2011 ha pasado al 6,1 por ciento en 2015, siendo el gasto en euros por habitante de 1.458 en aquél y 1.412 en $2015^{9}$.

Sin embargo, esta crisis del Estado social no proviene de factores externos. Es estrictamente un problema de sostenibilidad, de mantenimiento de los flujos financieros. Las amenazas que se ciernen no proceden de proyectos alternativos ni de posiciones críticas. La plena compatibilidad de un modelo economía de mercado con un Estado asistencial que cubre las disfunciones, desigualdades y las marginaciones que ese mercado puede generar se ha impuesto en Occidente hasta hacer hoy de él un rasgo característico de la cultura occidental. Las únicas objeciones que se hacen al Estado social no son a sus fundamentos, sus valores, objetivos o logros, sino a su propia estructura organizativa, a sus fuentes de financiación. Se constatan unos hechos y se advierten unos factores que amenazan

8 J. Esteve Pardo, Estado garante. Idea y realidad, Madrid, INAP, 2015, p. 8.

9 Ministerio de Sanidad, Servicios Sociales e Igualdad, Estadística de Gasto Sanitario Público, Madrid, 2015 , p. 2. 
a su propia sostenibilidad, entre los que destacan, resumidamente, su elevado coste, el difícil equilibrio entre eficiencia y equidad, ya que se necesita, para la redistribución de riqueza, tener en pleno funcionamiento el sistema productivo, la evolución demográfica y, por último, la globalización ${ }^{10}$.

En este contexto de dudas sobre la sostenibilidad del Estado social y la consiguiente crisis de los derechos sociales se vienen a desarrollar por la doctrina nuevas estrategias que permitan dotarles de mayor fuerza vinculante, tratando de delimitar un verdadero contenido normativo. Entre estas estrategias destaca, singularmente, la de la reforma constitucional, a través de la cual se deslindarían dentro de los principios rectores aquellos que por su naturaleza y directa conexión con alguno de los derechos fundamentales exigieran un trato normativo distinto, reforzando su fundamentalidad. Tal deslinde provocaría que el contenido esencial del derecho social quedara protegido frente a las decisiones del legislativo y del ejecutivo. Se buscaría no conquistar el derecho social en su plenitud, sino, al menos, algunos de sus rasgos esenciales ${ }^{11}$. Así, Rey Martínez aboga por transformar el derecho a la protección de la salud en un derecho fundamental de configuración legal, es decir, que no todos los desarrollos legales del derecho, sino solo algunos, pasarán a formar parte del núcleo constitucional. Tal manera de configurarlo evitaría tanto los excesos y una separación absoluta de lo económicamente posible como un control débil por parte de los Tribunales ${ }^{12}$.

En todo caso, las propuestas que se orientan en este sentido son muy cautas, porque se parte de la premisa de que un reconocimiento amplísimo de derechos puede acabar desvirtuando o degradando su mismo carácter «fundamental» ante las dificultades posteriores para su garantía efectiva en la realidad de las cosas y con mayor razón en tiempos de crisis financiera y equilibrio presupuestario. Los reconocimientos constitucionales no pueden inducir a error o confusión a los ciudadanos y generar falsas expectativas que no pueden cumplirse. Y, precisamente, entre tales derechos que avanzarían en el escalón destaca el derecho a la protección de la salud,

Desde una perspectiva más ético-política que jurídica, se propone, en términos similares a los ya comentados, distinguir dos niveles de derechos sociales, de manera que algunos de ellos sí pudieran alcanzar la cota de la fundamentalidad por su conexión, no tanto con el principio de Estado social, sino con el de Estado democrático. Así, el principio de Estado democrático exige la participación activa de todos los ciudadanos, de manera que éstos deben disfrutar de un mínimo de

10 J. Esteve PARdo, Estado garante. Idea y realidad, op. cit., pp. 16 a 18.

11 A. Barrero Ortega, "A vueltas con la exigibilidad de los derechos sociales», en A. Barrero Ortega (Coord.), Derechos sociales. Lecturas jurídicas en tiempos de crisis, Tirant lo Blanch, Valencia, 2017, pp. 82 y 83. Vid., también, J. García Roca, Pautas para una reforma constitucional, Aranzadi, Madrid, 2014, pp. 37 a 43.

12 F. Rey MartíneZ, «Protección de la salud, atención primaria y derechos fundamentales», cit., pp. 290 y 291. 
condiciones de vida que hagan factible tal participación. En defecto de la provisión de tales condiciones, se incumple el presupuesto que permite tildar al Estado como democrático. Si la noción de democracia procedimental exige el respeto por la participación política efectiva de todos los miembros del cuerpo político, éstos deben estar en condiciones materiales de ejercer realmente ese derecho. El primer paso, pues, para defender la justificación democrática del establecimiento de un primer nivel de derechos sociales en los que se admitiría un control robusto en garantía de la propia democracia consistiría en asociar la necesidad de garantizar ciertas precondiciones materiales con la posibilidad de participar efectivamente en el procedimiento democrático ${ }^{13}$. No es posible hablar de un auténtico Estado de derecho si éste no es democrático, y para que lo sea realmente, los ciudadanos deben gozar de un mínimo vital que preserve su dignidad y les permita participar, en la práctica del mundo real, en el juego democrático ${ }^{14}$.

El primer nivel de los derechos sociales, en el que se admitiría el citado control robusto, estaría integrado por las precondiciones materiales del procedimiento democrático, esto es, aquellas exigencias sociales cuya garantía es necesaria para la existencia de instituciones democráticas que funcionan bien. Entre estas precondiciones, se incluyen el cuidado médico primario a los que carecen de los necesarios recursos materiales ${ }^{15}$.

Para concluir, simplemente recordar, como un ejemplo más de la difícil naturaleza del derecho a la protección de la salud, que su relación con la libertad como principio y derecho es también harto compleja. Tal derecho, como derecho social, exige detraer recursos de determinado grupo de ciudadanos para destinarlos a las demandas de otros, es decir, supone limitar los recursos económicos de otros que son sostén ineludible de la libertad en sociedades de consumo como las nuestras. Sin embargo, constituyen, al mismo tiempo, y paradójicamente, posibilidades efectivas de libertad ya que ésta no puede ser entendida sin un mínimo de condiciones económicas que permitan ejercerla.

\section{EMPODERAMIENTO DEL INTÉRPRETE DE LA CONSTITUCIÓN Y CONSIGUIENTE DEBILITAMIENTO DEL DERECHO A LA PROTECCIÓN DE LA SALUD: LAS RAZONES DE LA PARADOJA}

Uno de los factores que creemos que ha incidido en el debilitamiento de la eficacia del derecho a la protección de la salud, ha sido el excesivo empoderamiento del actor encargado de su propia protección a través de la interpretación de la Constitución y por tanto de sus principios rectores, el Tribunal

13 L. Morales, Derechos sociales constitucionales y democracia, Marcial Pons, Madrid, 2015, p. 303.

14 J. PonCE SolÉ, «Reforma constitucional y derechos sociales: La necesidad de un nuevo paradigma en el Derecho público español», Revista Española de Derecho Constitucional, n. ${ }^{\circ} 111,2017$, p. 70.

15 L. Morales, Derechos sociales constitucionales y democracia, op. cit., p. 304. 
Constitucional, pese a que ello pueda resultar, prima facie, paradójico. Como es sabido, el constitucionalismo de la segunda mitad del Siglo Xx traslada a dicha institución un papel estelar dentro de la ingeniería constitucional, en ocasiones, incluso por encima del poder mayoritario. La última palabra la tendrá ya no el representante del pueblo sino este poder contra-mayoritario que emerge en Europa como lo hiciera un siglo y medio antes en Estados Unidos de América. La legitimidad dejará de ser ya esencialmente democrática, optándose por una legitimidad de resultados, siendo las decisiones legítimas en función de que resulten útiles para la defensa del valor sustantivo de la propia democracia y de la libertad individual. Una nueva democracia constitucional asentada no sólo en instituciones representativas, sino también de control. Una democracia no ya tan política sino más jurídica, en la que la norma constitucional no es sólo reflejo del pacto social, sino también instrumento esencial de control, en términos muy parecidos a los expresados por Elster en su metáfora de Ulises y las sirenas ${ }^{16}$.

Como reacción a las debilidades institucionales de la República de Weimar, en la que los derechos quedaron sin protección al creerse en el Derecho constitucional como una realidad salvadora que, por sí misma, aseguraba la libertad y el pluralismo, es decir, lo que se ha llamado «el exceso de confianza en la soteriología jurídica» ${ }^{17}$ y en la que también se asentó el postulado de que el principio de legalidad de la actuación administrativa los salvaguardaba de manera suficiente, creándose un sistema de protección frente a la vulneración de la ley por las Administraciones Públicas, pero no frente a la vulneración por aquella de los derechos fundamentales $^{18}$, y a la flagrante vulneración de la dignidad humana y de los derechos que se produjeron en la primera mitad de dicho siglo, los Tribunales surgidos al amparo de este nuevo modelo vendrán a adoptar una posición muy activa en la interpretación y garantía de la división de poderes, por un lado, y de los derechos fundamentales, por el otro.

Este nuevo activismo judicial, desconocido hasta entonces en el modelo constitucional continental y, precisamente, del que se apartó desde sus inicios el constitucionalismo surgido de la Revolución Francesa ${ }^{19}$, exigía una moderación

16 Elster recurre a la fábula de Ulises y las sirenas para desarrollar su idea de que en las modernas democracias la Constitución actúa como norma de autoconstricción. Señala Elster que, tras comprobar que nosotros podemos ser nuestro peor enemigo, procuramos atarnos a través de la Constitución para evitar vernos tentados por los cantos de sirena (demagogia). Las Constituciones serían, de este modo, mecanismos de precompromiso o autorrestricción, elaboradas por el cuerpo político con el fin de protegerse a sí mismo contra su previsible tendencia a tomar decisiones imprudentes. Vid. J. ELSTER, «Introducción», en J. ELSTER y R. SLAGSTAD, Constitucionalismo y democracia, FCE, México, 2001, pp. 40 y 41.

17 Véase el voto particular del Magistrado Rodríguez Zapata en la Sentencia 235/2007, en el conocido caso Librería Europa.

18 M. González Pascual, El Tribunal Constitucional alemán en la construcción del espacio europeo de los derechos, Civitas-Thomson Reuters, Cizur Menor, 2010, p. 20.

19 Como nos recuerda con gran acierto el profesor García de Enterría, originaria de la libertad y destinada a su servicio exclusivo, imprescindible para el gobierno humano, será la que intenten hacer valer los revolucionarios franceses. Es éste el punto decisivo en el que la Revolución Francesa se aparta de su modelo 
del Tribunal en otras esferas de manera que se equilibrara su papel y, precisamente, ahí es donde aparecen los derechos sociales. No es sólo que el propio constituyente les otorgue un papel y una eficacia distinta a la de los derechos y libertades, más próximos aquellos a principios que a verdaderas reglas, sino que también el Tribunal aprovechará la coyuntura para poder operar de manera activa en ocasiones y limitada en otras. Los derechos sociales y, singularmente el derecho a la protección de la salud, se convierten, así, en la excusa constitucional que impide que la nueva función que va a ir asumiendo sea considerada excesiva para los valores en los que se asienta esta nueva democracia constitucional que tampoco olvida del todo la división de poderes de la democracia representativa tradicional. Los derechos sociales acaban por convertirse en la excusa o salvaguarda del Tribunal frente a aquellos que consideren que el nuevo modelo puede orientarse hacia un excesivo activismo judicial.

\section{LA OBJECIÓN DEL TRIBUNAL DE JUSTICIA COMO ACTOR PRINCIPAL EN LA DISTRIBUCIÓN DEL GASTO PÚBLICO}

Cuando sectores de la doctrina se pronuncian a favor de la verdadera eficacia y operatividad jurídica del derecho a la protección de la salud, superando su carácter meramente mediato y no inmediato, o, en otras palabras, cuando se habla en términos metafóricos de blindarlo, ello se traduce en la pretensión de dotar al Tribunal Constitucional de pleno control y capacidad de decisión en relación de las posibles limitaciones a tal derecho adoptadas por los poderes legislativo y ejecutivo. El temor es que un Gobierno con suficiente respaldo parlamentario pueda, en el periodo entre elecciones, limitar el alcance de la protección de la salud a través de la reducción de la asignación económica exigida para su verdadera operatividad. Blindar supone, por tanto, permitir al Tribunal tener la última palabra.

De este modo, el problema acerca de la eficacia del derecho a la protección de la salud enlaza directamente con el principal debate al que se enfrenta en Europea el Derecho constitucional a partir del final de la Segunda Guerra Mundial, que no es otro que el de la legitimidad democrática de otorgar la función de intérprete máximo a un poder de constitucionalidad diferenciado y ya no a los representantes del pueblo constituidos en Parlamento. El constitucionalismo encierra desde la segunda mitad del siglo xx un doble compromiso difícil de cohonestar: un compromiso con la idea de derechos (dimensión sustantiva) y un compromiso con la idea de democracia (dimensión procedimental) ${ }^{20}$.

\footnotetext{
americano y del que van a resultar dos sistemas jurídicos distintos. Vid. E. García de EnTERría y A. Menéndez Menéndez, El Derecho, la Ley y el Juez, dos estudios, Civitas, Madrid, 2000, p. 31.

20 S. Linares, La (i)legitimidad democrática del control judicial de las leyes, Marcial Pons, Madrid, 2008, p. 45 .
} 
El debate acerca de su naturaleza y eficacia encierra por tanto otra discusión que conecta directamente no ya con la parte dogmática de la Constitución, sino con la parte orgánica de la Constitución. Ello se traduce en determinar cuáles son las facultades que, ope constitutione, disponen los Tribunales de Justicia y, especialmente, el Tribunal Constitucional al ejercer su función de control constitucional sobre las decisiones de los poderes legislativo y ejecutivo en materia de los derechos sociales. Y así, si consideramos que el derecho a la protección de la salud, pese a su naturaleza de derecho social, desarrolla una eficacia similar a la de los tradicionales derechos y libertades, conectando directamente, por ejemplo, con la dignidad que se consagra en el artículo 10 de la Constitución o con algunos derechos consagrados como fundamentales, como el derecho a la vida o a la integridad que se consagran en el artículo 15, será fácil admitir que los poderes públicos encuentran muy limitadas sus facultades de configuración de aquél, existiendo un control judicial que podemos tildar de fuerte. Tal posición es difícilmente sostenible en nuestro sistema constitucional e incluso en cualquier otro de similares características ya que ello supone dotar de importantes competencias en materia económica a los Tribunales, cuando la competencia económica corresponde al Parlamento y al Gobierno en la preparación, aprobación y ejecución de los Presupuestos del Estado.

El derecho a la protección de la salud constituye un derecho con alto contenido económico ya que su satisfacción no exige una mera abstención por parte de los poderes públicos, como ocurre con las clásicas libertades públicas que integran los denominados derechos de primera generación, sino la inversión de importantes partidas económicas para cumplir con su obligación de dar. Se trata de un derecho dependiente de la reserva de lo económicamente posible ${ }^{21}$, aunque ello sea, en palabras de Rey Martínez, su pecado original ${ }^{22}$. Si los derechos fundamentales sociales son vinculantes, conducen a un desplazamiento de la política social desde la competencia del parlamento a la del Tribunal Constitucional y debido a los efectos financieros de los derechos fundamentales sociales, y a causa de los considerables costos vinculados a su cumplimiento, la existencia de derechos fundamentales sociales amplios judicialmente imponibles conduciría a que la política presupuestaria estaría determinada, en parte esencial, por el Derecho constitucional ${ }^{23}$. Las actuaciones prestacionales de los Tribunales no suponen ejercicio de jurisdicción, sino que denotan un poder político que un órgano judicial ni tiene ni conviene que tenga en el Estado de Derecho donde ha de impedirse a la Justicia el desempeño de una función que no sea de mera aplicación de la ley ${ }^{24}$.

21 G. Escobar Roca, «Derechos fundamentales: una aproximación general», cit., p. 142.

22 F. Rey Martínez, «Protección de la salud, atención primaria y derechos fundamentales», cit., p. 287.

23 R. Alexy, Teoría de los derechos fundamentales, CEPC, Madrid, 2002, pp. 490 a 493. Vid., también, A. Zuñiga Fajuri, Justicia distributiva y derecho a la protección de la salud, Tesis doctoral, Universidad Autónoma de Madrid, Madrid, 2006, p. 51.

24 A. OrtegA, «A vueltas con la exigibilidad de los derechos sociales», op. cit., p. 85. 
Tal nueva posición que pudiera otorgarse a los Tribunales en pos de implementar la fuerza vinculante, no sólo es contraria a la propia naturaleza de la función jurisdiccional, sino que puede, incluso, afectar a la propia normatividad de la Constitución ${ }^{25}$. En todo caso, este argumento de índole económica encuentra algunas objeciones importantes, ya que expresar que los derechos sociales suponen un costo importante mientras que las libertades no, es una mera metáfora que responde más a criterios ideológicos que reales, como nos recuerdan Holmes y Sunstein cuando señalan que tanto las libertades como los derechos implican deberes positivos (costos) para el Estado ${ }^{26}$, siendo un ejemplo paradigmático de ello las libertades políticas y el coste de la celebración de unas elecciones generales como marco necesario para que aquélla se exprese o el coste de la seguridad a través de manteniendo de un sistema de orden público integrado por las fuerzas y cuerpos de seguridad del Estado. Todos los derechos son costosos porque todos presuponen una maquinaria eficaz de supervisión, pagada por los contribuyentes, para monitorear y controlar ${ }^{27}$.

Pese a que todo lo anterior es cierto, tampoco deja de serlo que un mero repaso de los Presupuestos del Estado que se aprueban en cada ejercicio sí nos permite apreciar que los derechos sociales, y singularmente el derecho a la protección de la salud, suponen una partida considerable del erario público, mientras que las libertades en su condición de esferas reconocidas y protegidas para la autodeterminación de los individuos pueden no tener coste o ser este poco considerable. Los derechos sociales, por el contrario, suponen siempre, no un deber de abstención como las libertades, sino una obligación de hacer o dar, lo que necesariamente conlleva un gasto público. Así pues, sin ser cierta la afirmación tan escuchada de que los derechos sociales cuestan y las libertades no, de manera que las facultades de decisión del poder legislativo y ejecutivo, en cuanto tributarios de las funciones económicas, deben ser mayores respecto de aquéllos que respecto de éstos, es difícil negar que el impacto económico de unos y otros es muy diferente en líneas generales. Como señala Ponce Solé, no se puede negar que algunos derechos sociales en cuanto a la obligación jurídica de darles satisfacción exigen un gasto público imprescindible para ello, asociado a la prestación de determinados servicios públicos ${ }^{28}$, y entre estos, destacaría uno respecto del que se exige mayor fundamentalidad, como es la salud, por lo que la pretensión de su reforma constitucional no puede obviar el problema económico que supone su garantía, con el impacto político que conlleva frustrar las expectativas creadas normativamente.

25 Ibidem, pp. 37 a 43.

26 S. Holmes y C. Sunstein, El costo de los derechos. Por qué la libertad depende de los impuestos, Siglo XXI, Buenos Aires, 2011, pp. 64, 65, 123 y 143.

27 Ibidem, pp. 64 y 65.

28 J. PONCE SOLÉ, «Reforma constitucional y derechos sociales: La necesidad de un nuevo paradigma en el Derecho público español», cit., p. 87. 
Pero es que, además, el problema de la eficacia de los derechos sociales frente a las tradicionales libertades no reside sólo en el coste en sí, sino en el propio pacto social en el que se sustentan las libertades tradicionales y los derechos sociales, y en el propio modelo económico abierto que recoge nuestra Constitución. Las libertades no pueden depender, en cuanto a su eficacia y protección, de la ideología que el Parlamento y el Gobierno sustenten por obra del mandato de sus representados. Caben ciertos matices, pero no podrán verse afectados, configurados o limitados los rasgos esenciales de aquéllas. El pacto social sobre las libertades es extremadamente sólido, ya que éstas suponen, precisamente, la precondición para alcanzar aquél, para justificar la limitación de la libertad que la sujeción al principio de la mayoría supone. Por el contrario, los derechos sociales no constituyen un pacto inamovible, sino que, en parte, dependen del programa socioeconómico del Parlamento y Gobierno que vienen sustentados en la mayoría. Blindar el poder de configuración de los derechos sociales puede suponer tanto como predeterminar una Constitución económica cerrada, sin posibilidad de mínima opción ideológica o política. Y, por ello, se distingue entre dos escalones o niveles de derechos sociales, admitiendo, según el escalón o nivel, un control robusto o débil, al conectarlos, bien con alguno de los derechos fundamentales, bien con el propio principio de Estado democrático, como precondiciones para su desarrollo.

Además, un control fuerte por parte de los Tribunales no parece tampoco admisible. Y ello, no sólo es debido a que éstos están pensados más para castigar las acciones estatales ilegales que para imponer a los poderes públicos actuaciones positivas $^{29}$, sino también si atendemos a cuáles son los elementos que caracterizan la decisión judicial frente a la decisión política. Mientras que los Tribunales han de resolver habitualmente un caso concreto, atendiendo a las específicas circunstancias que concurren en el mismo, el Parlamento y el Gobierno adoptan la decisión con una perspectiva más global, más general. Mientras a éstos les preocupa la visión de conjunto, una visión más holística que atienda a las necesidades de toda la comunidad, al Tribunal le preocupa el caso concreto, las singulares necesidades de un individuo o grupo de individuos, no el problema económico en su conjunto.

Los Tribunales no están familiarizados con la fiscalización de normas finalistas que se expresan en forma de objetivos a lograr sin pronunciarse acerca de los cursos de acción política y económicamente idóneos para conseguirlos. Todo ello aparece se recogido en la propia doctrina del Tribunal Constitucional cuando señala que la sostenibilidad del sistema sanitario público impone a los poderes públicos la necesidad de adoptar medidas de racionalización del gasto sanitario, necesarias en una situación caracterizada por una exigente reducción del gasto público, de manera que las administraciones públicas competentes tienen la obligación de distribuir equitativamente los recursos públicos disponibles y

29 G. EscOBAR RocA, «Derechos fundamentales: una aproximación general», cit., p. 143. 
favorecer un uso racional de este Sistema (ATC 96/2011, de 21 de junio, FJ 6). Los derechos prestacionales requieren una base financiera sólida y una administración de recursos escasos, permitiendo al legislador una amplia libertad de configuración (STC 245/2004).

Así pues, parece poco admisible en nuestro sistema de división de poderes que la decisión sobre el destino de partidas ingentes de dinero público que han de permitir el desarrollo y efectividad del derecho a la protección de la salud quede en manos de la decisión judicial.

Por lo tanto, todo control, cualquiera que sea la naturaleza de éste, de la decisión pública debe desarrollarse dentro del máximo respeto a dicho poder configurador que le es otorgado a los poderes públicos por la propia Constitución. Sin embargo, la ausencia de todo control judicial tampoco resulta satisfactoria porque ello implica que el derecho a la protección de la salud quedaría vacío de contenido al no quedar revestido de garantía alguna que permitiera un control por parte de los Tribunales de los límites que respecto de dicho derecho acuerden los poderes públicos. Se trata, por tanto, de buscar una solución de equilibrio entre un control judicial fuerte y la ausencia de control que dote a los poderes públicos de cierto margen de decisión, pero sin obviar de manera absoluta el control por parte de los Tribunales de Justicia.

\section{LA OBJECIÓN DE LA LITIGACIÓN COMO ELEMENTO PRINCIPAL DE JUSTICIA SOCIAL EN SANIDAD}

La propuesta que determinados sectores de la doctrina hacen para dotar de mayor eficacia al derecho a la protección de la salud mediante su transformación de derecho social en derecho fundamental encierra, como es obvio, la pretensión de dotar a los Tribunales de mayores facultades a la hora de controlar la constitucionalidad de las presuntas medidas limitadoras de dicho derecho por los poderes públicos. Se trata de que la última palabra no esté en boca del Parlamento o del Gobierno, en la configuración de las cuentas del Estado y del gasto público, sino en la de los jueces. Se pretende que el derecho sea fundamental, más allá que por razones de dogmática jurídica que quedarían vinculadas al concepto de las condiciones mínimas para el ejercicio de la libertad, por razones puramente pragmáticas. Transformarlo en fundamental significa dotarlo de una protección más extraordinaria a través del papel estelar que se otorgaría de facto a los Tribunales.

Esta propuesta supone también una confianza casi soteriológica en el papel que los jueces pueden desempeñar en nuestras democracias contemporáneas, lo que sin duda constituye una excepción al tradicional constitucionalismo europeo en el que, por obra de la revolución francesa, el poder judicial era visto con sospecha frente a la voluntad del pueblo que solo podía emanar del Parlamento. Se trata de fomentar una solución contramayoritaria por sectores doctrinales que en muchas ocasiones sostienen, paradójicamente, las virtudes de una democracia mayoritaria. 
Sin embargo, como vamos a explicar a continuación, el fortalecimiento del papel de los jueces en nuestras democracias a través de la transformación del derecho a la protección de la salud en un derecho fundamental no cumple un verdadero papel redistribuidor de los recursos sanitarios, ni tampoco atiende a satisfacer las necesidades de salud de los grupos sociales más vulnerables. Antes al contrario, convertir la litigación en el principal elemento de defensa y garantía del derecho provoca que los verdaderos beneficiados por ello sean las clases menos vulnerables, las clases medias y altas urbanas más acostumbradas y con más fácil acceso al litigio. Por otro lado, el objeto principal del litigio no es habitualmente el funcionamiento del sistema en su integridad, sino el caso concreto del acceso a un medicamento específico y, habitualmente, además, los de mayor coste. En definitiva, el litigio rara vez actúa como instrumento de distribución de los recursos públicos y de justicia social.

Para Flood y Gross el peligro de un enfoque de protección del derecho a la salud basado en la litigación de derechos es que puede incrementar las demandas individuales de tratamientos de alto precio, exacerbando así las dificultades que tienen los gobiernos para administrar sistemas de atención de salud justos y eficien$\operatorname{tes}^{30}$. Colombia puede mostrarse como el ejemplo paradigmático de ello. Ahí, tras adoptar los Tribunales una posición muy activa en la protección del derecho a la salud, el Gobierno ha perdido su poder para negociar los precios con las compañías farmacéuticas, los hospitales, los médicos y otros proveedores y el incremento de los costos del sector público ponen al propio sistema universal en riesgo, ya que tales derechos son tratados como derechos incondicionales e ilimitados.

En Brasil, el incremento de los litigios vinculados a tal derecho aumentó de un solo caso en 2002 en el que el sistema de salud se vio obligado a adquirir y ofrecer un medicamento como consecuencia de una reclamación judicial a casi nueve mil casos diez años después. La práctica totalidad de estos litigios están vinculados específicamente al acceso a determinados tratamientos farmacéuticos y no a decisiones de salud pública, como pudieran ser las vinculadas a la higiene y salubridad en las ciudades o al medioambiente. Además, los datos de Brasil muestran que no todos los ciudadanos están dispuestos a acudir a los Tribunales, de manera que los que realmente se ven beneficiados por el modelo asentado en la litigación no son precisamente los más necesitados. El modelo brasileño no parece que promueva la igualdad porque concentra los recursos en una pequeña parte de la sociedad, la que está integrada por las clases medias y superiores y, habitualmente, del ámbito urbano. Las clases más desfavorecidas y que viven en la periferia no se ven protegidos por un sistema en el que la litigación está ocupando un papel estelar ${ }^{31}$.

30 C. M Flood, C.M. y A. Gross, «Litigating the right to health: what can we learn from a comparative law and health care systems approach», Health and Human Rights Journal, vol. 16, n. ${ }^{\circ}$ 2, 2014, p. 69.

31 A.P. De BARCEllos, «Sanitation rights, public law litigation, and inequality: a case study from Brazil», Health and Human Rights Journal, vol. 16, n. ${ }^{\circ}$ 2, 2014, pp. 36, 42 y 43. La misma conclusion alcanzan con carácter general Cabrera y Ayala. Vid. O.A. Cabrera y A.S. AyalA, «Advancing the right to health 
En Argentina, las reclamaciones judiciales en este ámbito obtienen un elevado éxito, pero que queda siempre circunscrito al objeto de la reclamación, sin incorporar consideraciones adicionales que pudieran beneficiar a otros individuos afectados por las fallas o deficiencias del sistema de salud que la judicialización revela. La judicialización se ha limitado a operar como un mecanismo de protección de los derechos individuales, pero sin verdadera incidencia en las políticas públicas de salud. Y así, mientras el litigio por acceso a la atención de la salud mantenga su actual patrón individualista, difícilmente podrá desarrollar todo su potencial para garantizar el efectivo respeto por el derecho a la salud ${ }^{32}$.

En nuestra doctrina, Mir Puigpelat se ha mostrado crítico con el papel que puede jugar el litigio en un sistema de reparto de los recursos justo y equitativo. Y aunque su crítica va referida a un ámbito distinto del que nos ocupa a nosotros, sus argumentos también creemos que nos resultan muy válidos. Señala dicho autor, en su atinada crítica del instituto de la responsabilidad patrimonial objetiva que se asentó en nuestro sistema jurídico-administrativo en la década de los noventa, que es un lugar común en la doctrina administrativista española partidaria de la responsabilidad objetiva global de la Administración afirmar que dicho modelo se justifica por razones de solidaridad, siendo dicho sistema más progresista que otro basado en el elemento culpabilístico o de alcance más limitado $^{33}$. Sin embargo, la institución de la responsabilidad no es un buen instrumento de canalización de la solidaridad, no es una buena herramienta redistributiva; antes al contrario, la asignación masiva de recursos públicos a través de dicha institución solo perjudica a la solidaridad y a la redistribución, al desviarlos de sus flujos más acertados. La responsabilidad solo tiene en cuenta el daño producido y no otros factores como la situación socio-económica de la víctima y de su entorno, mostrándose, por ello, insensible, indiferente, ante los más necesitados y beneficiando por igual a ricos y pobres ${ }^{34}$. Añade Mir Puigpelat que aquel modelo realmente beneficia a las clases más ricas, ya que, como en muchas ocasiones para ver resarcido el daño no basta con la vía administrativa, sino que hay que acudir a la judicial, son dichas clases la que tienen más facilidad para litigar ${ }^{35}$.

Para concluir, resulta interesante destacar el estudio de Heymann y otros que ha analizado el estatuto jurídico del derecho a la salud en los ordenamientos constitucionales de ciento noventa y un Estados y en el que se concluye que existe una

through litigation», en J.M. Zuniga, S.P. Marks y Lawrence O. Gostin (Eds), Advancing the human right to health, Oxford University Press, Oxford, 2013, pp. 30 y 33.

32 V. Gotlieb, N. Yavich y E. BÁscolo, «Litigio judicial y el derecho a la salud en Argentina», Cad. Saúde Pública, Rio de Janeiro, vol. 32, n. ${ }^{\circ} 1,2016$, pp. 7 y 8.

33 O. Mir Puigpelat, La responsabilidad patrimonial de la Administración. Hacia un nuevo sistema, Civitas, Madrid, 2002, p. 242.

34 Ibidem, pp. 243 y 244.

35 Ibidem, pp. 246 y 247. 
discrepancia muy relevante entre el grado de protección constitucional y la aplicación de los derechos de protección de la salud, de manera que países con un alto mandato constitucional de protección de la salud de los ciudadanos cuentan con pobres registros en la aplicación de políticas y sus resultados, en tanto que otros países con menor compromiso constitucional registran mayores cuotas de protección efectiva de la salud ${ }^{36}$. Así pues, como puede comprobarse, mayor protección constitucional o mayor fundamentalidad del derecho a la protección de la salud no implica mejores resultados efectivos o mayor protección en la práctica de la salud, sino que, todo lo contrario.

En definitiva, el activismo judicial que pudiera estar en el objetivo de la transformación del derecho a la protección de la salud no satisface los principios de justicia y remoción de las desigualdades que se consagran en nuestro orden constitucional, como nos demuestra la experiencia de muchos países que iniciaron hace años dicha vía.

\section{CONCLUSIÓN: HACIA UNA FÓRMULA INTERMEDIA DE CONTROL DEL DERECHO A LA PROTECCIÓN DE LA SALUD}

Ni la ausencia de control por parte del Tribunal Constitucional ni un control fuerte parece mostrarse como razonable si atendemos tanto al impacto de ambas pudieran tener en la parte dogmática y orgánica de la Constitución. Por ello, la solución no creemos que radique en promover reformas constitucionales que alteren la naturaleza actual del derecho a la protección a la salud, dotándole de cierta fundamentalidad, con los problemas que para la división de poderes y para las funciones tradicionales de los Tribunales ello pudiera conllevar, o, incluso, para la propia sostenibilidad del sistema público de salud que quedaría al albur no ya de las decisiones políticas del ejecutivo y del legislativo, sino en manos de un poder judicial que actuaría insólitamente no como garante del derecho sino como verdadero mecanismo de distribución de los recursos en el ámbito de la protección de la salud.

La solución, pues, no es otra que acudir a las reglas tradicionales que nuestro sistema constitucional ha desarrollado en el ámbito de la limitación de los derechos, sin obviar que en el ámbito de los derechos sociales regirá un control algo más débil, al reconocerse a los poderes públicos un mayor poder configurador. No se trata de reformar, sino de exigir que por parte del Tribunal Constitucional se

36 J. Heyman, A. Cassola, A. Raub y L.C. Mishra, «Constitutional Rights to Health, Public Health and medical care: The status of health protections in 191 countries», Global Public Health: An International Journal for Research, Policy and Practice, vol. 8, n. ${ }^{\circ}$ 6, 2013, pp. 639 a 653. Vid., también, T. GómEZ FrANCO, «Del reconocimiento constitucional del derecho a la protección de la salud a su garantía efectiva a los ciudadanos en algunos países iberoamericanos», Revista Electrónica Iberoamericana, vol. 10, n. ${ }^{\circ}$ 1, 2016, p. 5 . 
ejerza un control adecuado, en los términos que le habilita una interpretación teleológica del texto constitucional.

Así, el recurso a la racionalidad material y formal en la evaluación decisión pública, lo que, de hecho, el propio Tribunal Constitucional tendría que emplear con carácter general en los casos de limitación de derechos, ya sean fundamentales o sociales, es el instrumento adecuado de control. El Tribunal al enjuiciar la racionalidad material y formal de la decisión pública, lo que viene a evaluar son los elementos tenidos en cuenta a la hora de adoptar la decisión limitadora.

El control fundamentado en la racionalidad material hace referencia al principio de proporcionalidad, que no queda excluido de operatividad por tratarse de meros principios rectores y no derechos en sentido estricto. Así lo ha proclamado el Tribunal Constitucional, entre otras, en la STC 139/2016, que somete la decisión del Parlamento de limitar el acceso a las prestaciones sanitarias por parte de los inmigrantes sin papeles a dicho principio: «dentro del margen del legislador de establecer sus prioridades, la norma examinada no responde a una opción arbitraria, sino a la preservación de bienes o intereses constitucionalmente protegidos, como el mantenimiento del sistema sanitario público, sin desconocer las posibilidades del sistema en un momento de intensas complicaciones económicas, observándose, en la distinción entre extranjeros con autorización de residencia y los que carecen de ella, la debida proporcionalidad y dando cumplimiento a las obligaciones internacionales en la materia».

También, en la STC 11/1981, cuando el Tribunal Constitucional hace referencia al concepto de núcleo esencial como límite a los límites a los derechos, no distingue de cara a su operatividad y, por tanto, a la del principio de proporcionalidad entre derechos fundamentales y libertades públicas y derechos sociales. Así, en su Fundamento 8, la Sentencia afirma sin ambages que «Para tratar de aproximarse de algún modo a la idea de "contenido esencial», que en el artículo 53 de la Constitución se refiere a la totalidad de los derechos fundamentales y que puede referirse a cualesquiera derechos subjetivos sean o no constitucionales». Así pues, la condición de derecho social sobre el que operara el límite no deja a la decisión del poder público exenta de verse sometida al test de proporcionalidad y a sus subprincipios de legitimidad, idoneidad, necesidad y proporcionalidad en sentido estricto y, por ende, al límite a los límites, el núcleo esencial.

De este modo, crear a través de la reforma constitucional una suerte de blindaje del derecho a la protección a la salud que garantizara frente a la decisión limitadora de los poderes públicos su contenido esencial no aporta nada a su defensa, ya que dicha garantía ya existe en el actual sistema constitucional. Cuestión distinta es que el Tribunal Constitucional no haya recurrido al principio de proporcionalidad a la hora de evaluar el límite o lo ha hecho en términos poco rigurosos. Un ejemplo paradigmático de esta dejación de control, la encontramos en la ya citada STC 139/2016.

En dicha Sentencia, el principio de proporcionalidad es citado explícitamente, pero de su lectura se concluye que más allá de la mera cita no se recurrió al mismo para evaluar la racionalidad material de la limitación del derecho a la 
salud que aquella norma supuso. Los subprincipios de adecuación y de necesidad eran poco superables cuando la decisión adoptada por el Gobierno sobre el derecho a la salud de los inmigrantes indocumentados poco o nada aportaba a las necesidades de recorte del gasto público, cuando el impacto económico que tal asistencia venía a implicar era nimio, una vez garantizada la asistencia a las mujeres embarazadas, a los menores y la asistencia de urgencia. El argumento esgrimido como motivación de la limitación del derecho a la protección de la salud es harto discutible, sobre todo, si acudimos al tenor literal del propio Informe del Tribunal de Cuentas al que tácitamente se remite el Preámbulo del Decreto-ley objeto de revisión constitucional. Del denominado Informe de fiscalización de la gestión de las prestaciones de asistencia sanitaria derivadas de la aplicación de los reglamentos y convenios internacionales de la Seguridad Social, de 29 de marzo de 2012, no puede deducirse que la asistencia a los emigrantes sin papeles fuera el problema en el que radicaba esa exigencia de aclarar la condición de asegurado, sino precisamente lo eran otros colectivos no tan desfavorecidos que acudían a nuestro país, bien por razones de turismo y ocio y se veían en la necesidad de requerir asistencia sanitaria o, incluso, aquellos otros que acudían única y exclusivamente para recibir dicha asistencia, lo que se ha denominado, turismo sanitario. En ninguno de ambos colectivos creemos que se puedan encontrar los emigrantes sin papeles, de manera que el Informe que el propio Gobierno manejaba en apoyo de su reforma carecía de toda virtualidad a tales efectos, mostrándose aquel como el único informe técnico o argumento formal esgrimido.

Tampoco quedó acreditado el impacto que tal medida habría de tener en las arcas públicas a los efectos de garantizar la sostenibilidad del Sistema Nacional de Salud, que sinceramente creemos que sería nimia si atendemos al hecho de que los emigrantes sin papeles responden a un perfil de edad que difícilmente les hará ser demandantes habituales de asistencia sanitaria, a diferencia por ejemplo de los ciudadanos comunitarios que vienen a disfrutar de su retiro en España y que suelen padecer, por razones de edad, enfermedades crónicas que sí demandan una asistencia sanitaria permanente o, al menos, más frecuente. Además, si algún tipo de asistencia sanitaria vendrían a demandar dichos emigrantes sin papeles sería precisamente la que el propio Decreto-ley les garantizaba, es decir, la asistencia en urgencias y la asistencia al embarazo y a los menores.

Así pues, no parece que los argumentos manejados por la norma objeto de análisis fueran mínimamente plausibles, pudiendo perfectamente afirmarse que la misma difícilmente podía superar el test de proporcionalidad, sobre todo por su falta de idoneidad, al dejar fuera de la asistencia a grupos necesitados de especial protección, y por afectar al núcleo esencial del derecho a la protección de la salud, con infracción del subprincipio de proporcionalidad en sentido estricto. Todo ello, fue, además, oportunamente denunciado por el voto particular a la citada Sentencia 139/2016, formulado por el Magistrado Valdés Dal-Ré,

En cuanto al principio de racionalidad formal, el mismo se traduce en una expresión del principio de interdicción de la arbitrariedad del legislador. Así 
pues, al Tribunal le corresponderá, sin imponer constricciones indebidas al Poder Legislativo y con pleno respeto a las opciones políticas, controlar el simple capricho, la inconsecuencia o la incoherencia, por falta de toda explicación racional. Y en la aplicación de este principio cobran especial relevancia las exposiciones de motivos de las iniciativas legislativas (art. $88 \mathrm{CE}$ ) y los preámbulos de las leyes. La falta total de fundamento y justificación de las medidas regresivas o el empleo retórico de apelaciones genéricas a la atención al contexto de austeridad y contención en el gasto público no deberían superar el test de interdicción de la arbitrariedad, salvo que, de alguna otra manera, y no por creación del Tribunal, se puedan constatar razones serias que ofrezcan soporte a la medida regresiva y evidencien ${ }^{37}$.

Junto a los principios de racionalidad material y formal, podría añadirse también la exigencia de atender en la evaluación del impacto del límite a cuáles son los grupos sociales afectados por la decisión, de manera que, como ya han declarado otras Cortes Constitucionales en relación con los derechos sociales, la protección de la vulnerabilidad operaría como un límite a los límites. Así, pueden citarse como verdaderos seminal cases en el Derecho constitucional comparado, la Sentencia del Tribunal Constitucional de Sudáfrica de 2002, caso Ministry of Health v. Treatment Action Campaigne, el cual versó sobre la constitucionalidad de la negativa de los poderes públicos a sufragar un fármaco, y la dictada por el Tribunal Constitucional de Colombia el 31 de julio de 2008. El Tribunal colombiano establece en su Sentencia que la decisión pública que limite el derecho a la protección de la salud puede ser controlada por el Tribunal cuando la misma recaiga sobre grupos sociales que sean susceptibles de una protección constitucional especial, es decir, grupos desfavorecidos o en peores condiciones que el resto de los ciudadanos para alcanzar unos mínimos vitales de subsistencia.

En nuestro ordenamiento constitucional, la operatividad del principio de protección frente a la vulnerabilidad se derivaría directamente de lo dispuesto en el artículo 9.2 en la medida a los poderes públicos a remover los obstáculos que impidan o dificulten su plenitud y facilitar la participación de todos los ciudadanos en la vida política, económica, cultural y social, lo que supone un deber especial de protección de los colectivos más vulnerables.

En definitiva, el problema acerca de la eficacia del derecho a la protección de la salud y el control de las decisiones de su limitación por los poderes públicos no responde a la ausencia de reglas que permitan en nuestro sistema constitucional un control de tales decisiones. Como hemos expuesto, los principios de racionalidad formal y material y el principio de protección frente a la vulnerabilidad pueden operar como reglas de control no robusto, pero en absoluto poco eficaces,

37 J. Ponce Solé, El derecho y la (ir) reversibilidad limitada de los derechos sociales de los ciudadanos. Las lineas rojas constitucionales a los recortes y la sostenibilidad social, INAP, Madrid, 2013, pp. 78 y 79. 
de las decisiones adoptadas por los poderes legislativo y ejecutivo en interpretación y desarrollo de tal derecho, sobre todo, en la medida que conecta con las condiciones mínimas de participación en el modelo democrático. El problema radica en que, en demasiadas ocasiones, el propio Tribunal Constitucional ha hecho un uso poco riguroso de los mecanismos de control que se le ofrecen.

$$
* * *
$$

TitLE: Fundamentality of the right to healthcare and sustainability of the public bealthcare system (when more can be less)

ABSTRACT: In the recent debate on the reform of the regulation of social rights in the Constitution and the rise of some of them to the category of fundamental rights, the right to healthcare takes on a prominent position. The proposal to transform the right to healthCARE into a fundamental right, although it could have positive effects from the perspective of ensuring the minimum conditions for the exercise of freedom, also presents problems related to the economic power that the proposal would give to the Court and to the increase OF litigation THAT IT would cause. On the other hand, our constitutional system has enough legal instruments to guarantee such social right without the need of transforming it into a fundamental right

RESUMEN: En el reciente debate sobre la reforma de la regulación de los derechos sociales en la Constitución y el ascenso de algunos de ellos a la categoría de derechos fundamentales, el derecho a la protección de la salud cobra un gran protagonismo. La propuesta de transformar en derecho fundamental al derecho a la protección de la salud, si bien pudiera tener efectos positivos desde la perspectiva del aseguramiento de las condiciones minimas para el ejercicio de la libertad, también presenta problemas en atención al poder económico que caería en manos de los Tribunales y al incremento de la litigación de provocaría tal reforma. Por otro lado, nuestro sistema constitucional tiene suficientes instrumentos legales para garantizar ese derecho social sin la necesidad de transformarlo en un derecho fundamental.

KEY WORDS: right to healthcare, social rights, constitutional reform, division of powers, principle of proportionality

Palabras clave: derecho a la salud, derechos sociales, reforma constitucional, división de poderes, principio de proporcionalidad

FECHA RECEPCIÓN: 12.04.2019

FECHA ACEPTACIÓN: 29.07.2019 